\title{
NOTAS
}

\section{Algunos dialectalismos espigados en la obra de Delibes}

Recogemos en este artículo algunos vocablos empleados por Delibes en diferentes obras suyas que, quizás por su carácter dialectal, no están incluidos con la acepción que se cita en la última edición del diccionario académico. Con cada término escogido intentamos documentar la extensión de su uso, relacionarlo con palabras de su misma familia léxica y, en ocasiones, dilucidar su etimología.

ACARREAR. - Transportar las mieses desde las tierras de labor hasta la era. Tiene un significado más restringido, por tanto, que el recogido por la Academia: "Yo me recuerdo acarreando a los cinco años, levantándome todos los días a las dos de la mañana" (Castilla habla, Madrid, 1986, p. 27) ${ }^{1}$.

Era vocablo de uso general en Tierra de Campos ${ }^{2}$, donde solía pronunciarse con una $e$ muy cerrada, hasta tal punto que se formaba un diptongo con la $a$. También se usa esta variante en Toro, según González Ferrero ${ }^{3}$. En Aragón y Navarra se emplea carriar. Deriva de carro.

AMONARSE.-Encogerse, agazaparse, acobardarse: "La liebre de enero es desconfiada: o se amona ante la proximidad del hombre o arranca larga" (El último coto, Madrid, 1992, p. 238).

El DRAE da para el término la acepción de 'emborracharse'. En este mismo sentido, Covarrubias, al explicar los efectos que provoca la embriaguez en los monos, comenta que a veces el exceso de vino ocasiona que los simios se retiren a un rincón, se encapoten y se cubran el rostro con las manos, por lo que quizás estemos ante una acepción figurada a partir de la reconocida por el diccionario académico. Sin embargo, el verbo ha podido formarse partiendo de algún otro significado de mono o mona.

1 Las palabras están puestas en boca de Darío Espinosa, un anciano de Sedano.

2 Sara García Bermejo, "Contribución al vocabulario de Tierra de Campos, RDTP, II (1946), pp. 474-488.

3 Juan Carlos GONZÁlez FerRero, Palabras y expresiones en el babla de Toro (Zamora) (Toro, 1990). En adelante lo citaremos como GF. 
Así, habrá que tener en cuenta el de 'persona de baja estatura', muy presente en el español de los Siglos de Oro; o el de 'imitador', ya que con frecuencia el vocablo se aplica para aludir a la conducta mimética de ciertos animales (conejos, liebres, perdices...) que se aplastan para confundirse con el terreno; o en fin, el señalado por el Diccionario de Autoridades para la expresión quedarse becho un mono 'quedarse corrido o avergonzado por alguna especie que le sobrecoge'.

Esta palabra también se usa en El Rebollar (Salamanca) y en las comarcas de Villalpando y Medina del Campo ${ }^{4}$. Indiquemos, por último, que González Ferrero recoge en Toro amonar 'mecer al niño acurrucándole en el regazo', y Cándido Sánchez León en Salamanca da la acepción de 'matar', 'dejar como muerto' para el mismo término 5 .

ÁVATE.-Es una interjección que se emplea para expresar la sorpresa, admiración, escándalo o mofa que provoca una persona o una determinada conducta. Equivale al coloquial anda que: "Y ávate con los gitanos. De que caen cuatro gotas, invaden la provincia, que yo creo que llegan hasta el Escudo, no vea fiebre igual" (Castilla habla, p. 114) ${ }^{6}$.

Estamos ante un significado trasladado a partir del clásico 'apártate'. El vocablo parece derivar de apage 'quita' y se relaciona, por lo tanto, según García de Diego, con los verbos abar y jabar, 'apartar', muy utilizados en el habla de Salamanca. El término, un imperativo en su origen, suele aparecer acompañado de pronombres enclíticos, casi siempre de segunda persona del singular, aunque Covarrubias registra también avaos y Timoneda ábalos (Sarao de amor, Valencia, 1561, fol. 37). La acepción con la que se emplea en el texto citado de Delibes goza de bastante difusión, pues está recogida en Tierra de Campos ${ }^{7}$, en las montañas de León y en las de Santander ${ }^{8}$.

4 Véanse, respectivamente, Ángel IGLESIAS OVEJERO, El habla de El Rebollar. Léxico (Salamanca, 1990), en adelante IO; Luciano LóPEZ GutiérReZ y Araceli GODINO LóPEZ, "Notas y testimonios sobre un manojo de términos vigentes en el habla de Villalpando", AIEZ, 1995, pp. 533-556, en adelante L y G; Ignacio SÁNCHEZ LÓPEZ, "Vocabulario de la comarca de Medina del Campo", RDTP, XII (1966), pp. 239-302, en adelante IS.

5 Cándido SÁNCHEZ LEÓN, Palabras y expresiones usadas en la provincia de Salamanca (Salamanca, 1995), en adelante CS.

6 Esta frase la pronuncia Gregorio Rodríguez, natural de Sedano.

7 Obsérvese su uso en Modesto AlONSO EMPERADOR, Estampas pueblerinas de la Tierra de Campos (Palencia, 1978, p. 165): "Y ábate lo que cobran por esas primas... que le sale a uno un grano".

8 Consúltense, respectivamente, MORÁN BARDÓN, "Vocabulario del Concejo de la Lomba en las montañas de León", BRAE, XXX (1950), pp. 155-168, 313-330 y 439-456, 
BÁLAGO.-La mies desde que se siega hasta ser trillada: "Un pesado olor a cieno entremezclado con el del bálago se cernía sobre los campos" (Las ratas, Barcelona, 1991, p. 167).

Para el DRAE este vocablo alude en unos sitios a la paja larga de los cereales desprovista del grano, y en otros lugares a la paja trillada; y efectivamente, tanto Covarrubias, como Francisco del Rosal y el Diccionario de Autoridades recogen el término con la acepción de 'especie de paja'. Sin embargo, en Tierra de Campos y zonas limítrofes se emplea con el significado usado por Delibes ${ }^{9}$. Asimismo, en Villacidayo (León), Millán Urdiales recoge la acepción de 'la mies una vez transportada a la era y descargada allí', y en Salamanca, Lamano y Beneite la casi idéntica de 'mies amontonada en la era antes de trillada'. Su etimología no está nada clara, pues para Corominas deriva de una voz céltica afín al bretón balazn y al galés banadl 'retama', mientras que García de Diego explica su origen a partir del latín vulgar palica 'paja', procedencia difícilmente demostrable.

BEZADO.-Cabestro: “Ve ahí tiene a los bezados que sueltan en las capeas de los pueblos, bueyes son, pero embisten lo mismo que un toro bravo" (Castilla habla, p. 105) ${ }^{10}$.

El vocablo está relacionado con vezo 'hábito, costumbre' y con el arcaico vezar, variante de avezar 'acostumbrar, adiestrar', hasta tal punto que parece un participio sustantivado de dicho verbo.

Ya se empleaba a comienzos del siglo xvir, según se desprende de la siguiente cita de Del Rosal: "Hoy llaman bezados a los toros domados, que en ganado menor llaman mansos".

En la Égloga VII de Juan del Encina aparece el vocablo con la acepción de 'animal que guía el rebaño', aunque por el contexto da la impresión de que alude a un carnero:

Queda, queda acá el vezado.

Helo, va por aquel cerro.

s.v. abar, en adelante MB; y GARCíA LOMAS, El lenguaje popular en las montañas de Santander (Santander, 1949), en adelante GL.

9 Véanse tres ejemplos sacados de otros tantos libros costumbristas del sector señalado: "Verías en el verano pasar los carros con el bálago a la era" (Agapito ModRoÑo AlONSO, Crónicas de ayer y de boy desde un pueblo zamorano, Zamora, 1993, p. 34).

"Los montones de bálago se extienden con una horca de madera de dos guijos para que quede preparada la trilla" (Modesto ALONSO EMPERADOR, op. cit., p. 78).

"Y ya en la era, tiraban la mies y preparaban la trilla del bálago acarreado" (MARTín-CALERo, Usos y decires de la Castilla tradicional, Valladolid, 1992, p. 50).

10 El término lo usa Jesús García, de Bercero, pueblo próximo a Tordesillas. 
Arremete con el perro

y arrójale tu cayado,

que anda todo desmandado.

La palabra se usa todavía en la comarca de Villalpando (L y G) y de Medina del Campo (IS). Gordaliza, por su parte, recoge en Palencia una acepción figurada 'toro de lidia manso', y Soledad Díez registra en León la expresión da avezao como aplicada a las personas y cosas por las que se siente cariño y avezase indicar que una persona o animal ha adquirido una mala costumbre' ${ }^{11}$.

CACHA.-Cayado: "¿Ves esa lasca blanca a dos metros de la cacha? Ve, ahí está aculada la zorra de ella" (Las ratas, p. 30).

Según Vicente García de Diego deriva de caia 'vara, garrote'. Sin embargo, también podría proceder de *cappŭla por alusión a la curvatura o asidero del cayado, aunque no es descartable que se trate de un derivado regresivo de cachava. El término se usa mucho en Tierra de Campos (L y G) y en todo el territorio del antiguo leonés, pues está documentado en vocabularios de La Maragatería, El Bierzo, Babia y Laciana ${ }^{12}$ y Salamanca (CS).

CHITAS.-Pezuñas de los cerdos: "Se alzó un desagradable olor a chamusquina y, al concluir, el Mamertito, el chico del Pruden, y los sobrinos de la señora Clo descalzaron al bicho y comieron las chitas" (Las ratas, p. 50).

Efectivamente, era costumbre en Tierra de Campos que los chicos esperasen impacientes que se terminara de chamuscar el cerdo para que les entregasen las pezuñas (calzado) a modo de chuchería. Lo explica muy claramente Alonso Emperador: "En la misma operación se le arrancan las pezuñas que, tiradas al suelo, son disputadas por un grupo de chiquillos que presenciaba el sacrificio (...). Yo ignoro si el chicle americano resultará más sabroso que aquella sucia capa córnea que sirviera de zapatos en vida del animal y me asalta la duda por la satisfacción con que mastican aquella golosina" (op. cit., p. 106).

Molinero Lozano ${ }^{13}$ recoge la palabra con la acepción de 'uñas del cerdo' en Fuentesaúco. En cambio, este mismo vocablo se usa en la comar-

11 Véanse, respectivamente, Roberto GORDALIZA APARICIO, Vocabulario palentino (Palencia, 1988), en adelante RG; y M. ${ }^{2}$ Soledad Dízz SuÁREZ, Léxico leonés (León, 1994), en adelante SD.

12 Véase Eugenio Miguélez Rodríguez, Diccionario de las bablas leonesas (León, 1993); en adelante MR.

13 Manuel Molinero LOZANO, "Algunas voces de Zamora", RDTP, XVII, 1961, pp. 548-557; en adelante ML. 
ca de Medina del Campo (IS) y en Villalpando (L y G) con el significado de 'pezuñas de las ovejas', y en Hinojosa de Duero (Salamanca) con el de 'pezuña de vaca', según Espinosa (Arcaísmos dialectales). Quizá tenga relación con chita 'taba, hueso del tarso de una res'.

CUCAR.-Se predica de los nogales cuando ya se han formado enteramente las nueces en ellos: "Aquel año los nogales empezaron a cucar en la segunda quincena de agoston (Los nogales, incluido en Castilla, lo castellano y los castellanos, Madrid, 1995, p. 122).

García Lomas en su libro El lenguaje popular en las montañas de Santander recoge cucar y su variante encucar con idéntico significado. Es evidente que este verbo se ha formado a partir de cuco o cuca 'nuez', vocablos también registrados por el erudito santanderino.

El término cucar, no obstante, aparece en el refrán San Lucas, ¿por qué no cucas? Porque no tengo las bragas enjutas, recogido por Del Rosal y Gonzalo de Correas. Para el primero, cucar vale lo mismo que beber y lo deriva del griego kukan 'brindar, beber', mientras que para el segundo estamos ante una de esas palabras expresivas que se "acomoda al propósito que se quiere.

Covarrubias, a su vez, recoge cucas 'medula de la fruta de cáscara', 'piñones mondados', 'chufas' y en Palencia cuca es equivalente hoy a golosina (RG).

Sobre todo, en la parte norte de Castilla-León y Santander menudean las voces relacionadas con el verbo objeto de este comentario. Así, el propio Delibes en su cuento citado usa escucar 'quitar el concho a las nueces' y escucador 'el encargado de esta operación'. En Barruelo, según Merino Bravo ${ }^{14}$, escucar vale lo mismo que quitar la cáscara, y en Santander García Lomas deja constancia de la existencia de cucal 'nogal' y acucarse 'formárseles a las vacas en las ubres unos tumores del tamaño de las nueces'.

Indiquemos, asimismo, que tuto, voz que en Tierra de Campos y en el ámbito del leonés tiene las acepciones de 'huevo' 'cascarón vacío del huevo' y 'testículo' parece una variante de cuco.

ENVERRONARSE.-Se predica este verbo del tocino sabroso y de buen comer: "Y su objetivo al capar un gocho no era solo para que engordase sino para que el tocino enverronase, cogiera gusto, que aquí decimos enverronado al tocino de buen paladar" (Castilla babla, p. 103) ${ }^{15}$.

14 Francisco Merino Bravo, Sopla el viento de la sierra (Palencia, 1986).

15 Las palabras se atribuyen a Salvador de la Viuda, vecino de Mayorga de Campos. 
Pudiera derivar de verrón 'cerdo semental', término que ya se encuentra en el medieval Libro de Alexandre y en el diccionario de Francisco del Rosal con la acepción de 'espuma': "De donde dicen berrón a la espuma, por la que este echa por la boca cuando anda en celos". Según el DRAE, verrón está relacionado con verres 'cerdo'.

Sánchez León (Salamanca) da una definición distinta para su voz emberronarse allegar un animal cerril al estado de coma, e incluso a la muerte, cuando se nota impotente para defenderse o huir.

Por nuestra parte, hemos comprobado en Villalpando el empleo de este verbo para referirse a la vaca o el toro bravo que llega al paroxismo por encontrarse acorralado e indefenso, y asimismo, también hemos registrado el término con la acepción de 'obsesionarse, obcecarse' (L y G).

GALÁPAGO.-Enfermedad hepática de las ovejas que se manifiesta en la formación de piedras y parásitos en el hígado: "La oveja que come centellas cría galápago en el hígado y se inutilizan (Las ratas, p. 139).

El vocablo se usa con idéntica acepción en las comarcas de Villalpando (L y G) y Medina del Campo (IS) y en la provincia de Palencia (RG). Sin embargo, Sánchez León lo recoge en Salamanca con el significado de 'tumor del ganado vacuno', y para el DRAE el término alude a una enfermedad propia de las caballerías que se localiza en el casco y parte de la corona.

Corominas considera que galápago puede proceder de la voz de origen prerrománico *calappăcu, emparentada con *calapaccěa 'calabaza' y carapaccèu 'caparazón' a través de una raíz común que serviría para designar a distintos objetos y seres cubiertos por una cáscara o cubierta dura y seca.

MANGAR.-Agarrar, coger, asir: "El Picaza aclaró que sin quitarle mérito al señor cura él le había visto sangrar por la nariz cada vez que se mangaba un catarro" (La boja roja, fragmento incluido en Castilla, lo castellano y los castellanos, p. 180).

También se usa este término con la acepción señalada en la comarca de Villalpando ( $\mathrm{L}$ y G) y en Salamanca (CS e IO). Puede derivar de mango.

REBARCO.-Hondonada situada entre montañas, vaguada: "Aquí, en los rebarcos, hay pinos de estos muy curiosos (...) mientras los de las laderas quedan pilongos, aguantan pero no medran" (Castilla habla, p. 149).

El $D R A E$ recoge barco 'barranco poco profundo' pero no indica nada sobre la extensión de su uso. Sin embargo, González Ferrero recoge en Toro barco 'valle, tierra entre alturas' y apunta la posibilidad de que se 
trate de un occidentalismo ${ }^{16}$. Además, en este mismo sentido hay que indicar que en la comarca de Villalpando se emplea barqueada 'hondón que tienen algunas tierras de labor' ( $\mathrm{L}$ y G) y que en el páramo burgalés se emplea barconada como equivalente a valle. "Recuerdo que en Monte Grande, que es un terreno con una barconada, un vallejo, pero todo pastizal, se ponía el pastor de Quintana en la peña, arriba" (Justo Peña y Antonio Zavala, El pastor del páramo, Oyarzun, 1995, t. I, p. 86). Deriva de barco.

SARRACINA.-Destrozo, estropicio, escabechina, matanza: "iHuy madre, las sarracinas que habre armado yo! Tenga por seguro que en los buenos tiempos sí que cazaba cien avutardas al año" (Castilla habla, p. 48$)^{17}$.

El término, con toda seguridad, deriva de sarraceno, debido a las devastadoras y brutales correrías atribuidas a ellos. Para el $D R A E$ el vocablo tiene la acepción de 'pelea entre muchos, especialmente cuando es confusa y tumultuaria'. Sin embargo, en la comarca de Villalpando (L y G) se emplea la variante zarracina con el mismo significado que en Delibes, y en León esta misma variante tiene la acepción más concreta de 'matanza de ganado' (MB). Por otra parte, en Sayago (ML) se emplea cerrecina 'considerable daño, sobre todo en los sembrados'; en Santander (GL) cerracina 'destrozo' 'zurra', y en León (SD) cerrajina 'destrozo'.

TRULLO.-Se aplica esta palabra como segundo término de una comparación para indicar lo gordo que está un ser humano o un animal: "Los bichos estaban gordos y lustrosos como trullos" (Las perdices del domingo, p. 147).

Abundio García Caballero recoge la expresión estar como un trullo en la zona que se extiende entre el curso medio del Valderaduey y el curso bajo del Cea, y comenta que se usa para referirse a alguien que está muy gordo, quizás por comparación con trullo o trujal 'tinaja donde se fabrica el jabón' ${ }^{18}$. Puede derivar de torculum 'trujal', vocablo emparentado con extorculare 'estrujar', y primitivamente 'exprimir en el trujal'. Si ello fuera así, la presencia de la palatal (ll), en lugar de la velar fricativa sorda $(j)$, habría que explicarla por probable influjo del leonés, más si se tiene en

${ }^{16}$ El propio Delibes utiliza barco probablemente con el significado de 'hondonada': "El terreno dibujaba un barco profundo y el animal, herido, lo franqueó a la pata coja como pudo" (Las perdices del domingo, Barcelona, 1981, p. 69).

17 Interviene Eusebio Marcos, vecino de Paredes de Nava.

18 Abundio García Caballero, Localismos (Valladolid, 1992). 
cuenta que por tierras de León se usa el término con la acepción de 'cordero que está excesivamente gordo' (MR).

Sin embargo, también podríamos estar ante la palabra trullo 'especie de pato', voz que proviene del latín truo -onis, que a su vez deriva de trua o trulla 'vasija'. Repárese, además, en que este último vocablo se encuentra en Del Rosal y en Juan del Encina ${ }^{19}$ con la acepción de 'vasija, fuente para beber el vino'. No obstante, esta etimología no parece probable.

\section{LUCIANO LÓPEZ GUTIÉRREZ \\ $\mathrm{y}$ \\ ARACELI GODINO LÓPEZ}

19 Poesia lírica y cancionero musical, edic. R. O. JONES y C. R. LEE (Madrid, 1979), p. 183. 